\title{
Uma partida em imagens: Instagram, Futebol e Materialidades da Comunicação
}

\author{
A match in images: Instagram, Football \\ and the Materialities of Communication
}

Ronaldo Helal I rhelal@globo.com

Professor Associado da Faculdade de Comunicação Social da Uerj e do Programa de Pós-Graduação em Comunicação da Uerj. Colíder do grupo de pesquisa "Esporte e Cultura", cadastrado no CNPq. Possui mestrado em Sociologia - New York University (1986) e doutorado em Sociologia - New York University (1994). É Pós-Doutor em Ciências Sociais pela Universidad de Buenos Aires (2006). É pesquisador do CNPq.

Fausto Amaro I faustoarp@hotmail.com Graduado em Comunicação Social, com habilitação em Relações Públicas, pela Universidade do Estado do Rio de Janeiro. Mestrando do Programa de Pós-Graduação em Comunicação da Uerj com bolsa Capes. Atua no projeto de pesquisa "Meios de Comunicaçao, Idolatria, Identidade e Cultura Popular", onde foi bolsista Pibid CNPq por mais de um ano, sob orientação do Professor Ronaldo Helal. Também participa como voluntário do projeto "Tecnologias de comunicação, entretenimento e competências cognitivas na cibercultura", sob orientação da Professora Fátima Régis. É um dos editores do blog "Comunicação, Esporte e Cultura".

Débora Gauziski I deboragauziski@gmail.com Mestranda em Comunicação pelo PPGCom/Uerj. Bolsista Capes e membro do grupo de pesquisa Arte midiática: dinâmicas estéticas e comunicativas na cidade contemporânea, coordenado pelo professor Fernando do Nascimento Gonçalves. Especialista em Jornalismo Cultural pela UERJ e graduada em Comunicação Social (habilitação Jornalismo) pela Universidade Estácio de Sá.

\section{Resumo}

Os trabalhos acadêmicos em Comunicação no Brasil que enfocam o Esporte possuem tradicionalmente uma abordagem ligada à sociologia clássica, tratando normalmente de representaçóes sociais e teorias jornalísticas, tendo como método principal a análise do discurso midiático. No presente artigo, rompendo com esse paradigma, investigamos as formas de apropriação do Instagram, aplicativo de compartilhamento de imagens, por torcedores de futebol. A partir de algumas tags, referentes à final da Libertadores 2012, efetuamos uma investigação acerca da produção de presença nas fotos postadas.

Palavras-Chave: Instagram; futebol; imagem.

\begin{abstract}
The Brazilian academic papers in Communication that focus on sports have their traditional approach linked to classical sociology, usually dealing with social representations and journalistic theories, having as main method the analysis of media discourse. In this paper, breaking with this paradigm, we investigate ways of appropriation of Instagram, a photo sharing application, by football fans. From some tags related to the final of the championship Libertadores 2012, we carried out an investigation on the production of presence in the photos posted.
\end{abstract}

Keywords: Instagram; football; image. 


\section{Introdução}

No cerne das Ciências Sociais e Humanas estaria em curso uma mudança no paradigma epistemológico e metodológico. Enquanto a Sociologia Clássica, herdeira do pensamento e do método de Émile Durkheim, foca-se no sujeito - no homem como o grande eixo sob o qual o mundo gira e enquanto único produtor de sentido -, a "nova" Sociologia, vinda do resgate dos ideais de Gabriel Tarde por Bruno Latour e outros autores, pleiteia um olhar mais detido para os objetos (os não-humanos ou inumanos), uma vez dotados de agência e em constantes associaçóes com os entes humanos, nas chamadas redes sociotécnicas (LATOUR, 2005). A própria noção de modernidade e pós-modernidade é posta em xeque por esses autores ${ }^{1}$, vide o livro Jamais fomos modernos (LATOUR, 1994).

Outro deslocamento presente nessa sociologia das associações (LATOUR, 2005) ou sociologia das ciências e das técnicas (CALLON, 1997) está na abordagem metodológica. Ressalta-se que a tradição moderna ocidental adota a hermenêutica, na interpretação ${ }^{2}$ de textos e imagens, como fonte primordial de obtenção do conhecimento e método legítimo de seu fazer científico. Bruno Latour, Steven Shaviro, Michel Callon, Hans Gumbrecht e outros teóricos, por sua vez, mudam a perspectiva na descrição dos objetos pesquisados. Para esses autores, devemos esgotar um objeto por meio justamente de sua descrição. No decorrer desse processo descritivo, encontraríamos as respostas e achados que procurávamos inicialmente, ou náo, mas apostas erradas também fazem parte da ciência.

Um dos principais autores a documentar esse processo de "virada" epistemológica e empírica foi Hans Ulrich Gumbrecht. Em seu livro Produção de Presença $(2010)^{3}$, logo nos dois primeiros capítulos, fornece aos leitores um elucidativo panorama dessa dicotomia entre modos de fazer ciência, com a reuniáo de um corpo de pesquisadores que refletiam sobre a dimensão material dos objetos. Gumbrecht é adepto da teoria das materialidades, que, apesar das proximidades com a Teoria Ator-Rede de Latour, não é a mesma coisa que ela. Ambas se assemelham primordialmente na atenção aos suportes e no reconhecimento de sua importância.

No campo da Comunicação e Esporte, onde esse artigo se encaixa, os trabalhos utilizam-se majoritariamente de uma perspectiva clássica, como demonstraremos à frente, seja em abordagens históricas ou sociológicas. Tentamos aqui propor um novo olhar para essa interface, seguindo a linha dos autores das materialidades.

Deste modo, neste trabalho, nos propomos a analisar as formas de apropriaçáo do Instagram, aplicativo de compartilhamento de imagens, por torcedores de futebol. A partir de algumas tags referentes à final da Libertadores 2012, efetuaremos uma investigaçáo acerca do conteúdo e da materialidade das fotos postadas. Como principal referencial teórico, utilizaremos as contribuiçôes do alemão Hans Gumbrecht nos livros Elogio da Beleza Atlética e Corpo e Forma, onde ele propóe um novo caminho para estudar o esporte.

Na primeira parte do artigo, abordaremos mais detidamente essa virada epistemológica em direção a uma nova sociologia, documentando sucintamente o que alguns autores das Materialidades propuseram sobre ela. Em seguida, traçaremos um panorama dos estudos no campo da Comunicação e Esporte, 
atentando para os autores citados e perspectivas teóricas trabalhadas nessa interface. Aqui, traremos ainda a contribuição de Gumbrecht para pensarmos o esporte por outro viés. $\mathrm{Na}$ terceira seção, abordaremos a questão da produção de presença através das fotos postadas pelos usuários do Instagram. Por fim, virá a pesquisa empírica, propósito primeiro desse artigo.

\section{Cultura de Presença ou Prestando Atenção no Mundo Material}

Nesse primeiro tópico, desejamos elaborar um breve panorama das materialidades e do crescimento da importância dos não-humanos nas teorias sociais, focalizando principalmente nas proposiçôes de Hans Ulrich Gumbrecht. E se ainda há dúvidas sobre a real necessidade de tratar dessas teorias para falar do esporte, indagamos o que seriam a bola, as luvas, chuteiras, carros, cavalos, lanças, armas, óculos, tacos, raquetes, traves, senão inumanos dotados de tal agência que os torna essenciais para o desempenho de todas as modalidades esportivas. A importância das materialidades pode ser resumida assim: "as condiçôes concretas de articulação e de transmissão de uma mensagem influem no caráter de sua produção e recepção" (ROCHA, 1998, p. 18). "O conceito quer repensar a hermenêutica, pressupondo uma dicotomia entre materialidade, uma presença das coisas e situaçôes num nível de 'realidade' fora da interpretação, e, de outro lado, as respectivas interpretaçôes” (HANKE, 2006, p. 2).

O pensamento sobre as materialidades começou a "ganhar corpo" com os colóquios organizados na década de 1980 por Gumbrecht em Dubrovinik (cidade da Iugoslávia). Pode-se dizer que uma proposta de superação da hermenêutica como metodologia hegemônica saiu das cinco ediçôes desse evento, reunidas no livro Materialities of Communication, organizado por Gumbrecht e Karl Pfeiffer (1994). Atualmente, essa corrente teórica está sendo desenvolvida por "pesquisadores do Departamento de Literatura Comparada da Stanford University" (FELINTO, 2001, p.1). A despeito da importância desses pesquisadores da literatura, Simone de Sá reforça uma genealogia da materialidade dentro dos estudos comunicacionais; não nega a contribuição da Literatura, mas antes "contextualiza sua reflexão" (2004, p. 3).

Essa mudança foi denominada por David Wellbery de "crítica pós-hermenêutica" e tinha alguns pontos-chave de reflexão, quais sejam: "exterioridade, medialidade e corporalidade" (ROCHA, 1998, p. 20, grifos do autor). Em poucas palavras um campo não-hermenêutico se funda no seguinte pressuposto: "a possibilidade de tematizar o significante sem necessariamente associá-lo ao significado" (GUMBRECHT, 1998, p. 145, grifos do autor). A materialidade dos significantes, mais explorada aqui teoricamente, é, para Gumbrecht, apenas um dos quatro campos em um "mapa não-hermenêutico" e é nela que se inclui a materialidade da comunicação (Ibid., p. 146-147). Sobre esta, Gumbrecht dirige as seguintes palavras: "Se tem algum encontro científico que eu presenciei que merece o elogio de ter sido 'instigante', 'importante', 'produtivo', foi o colóquio sobre materialidade da comunicação na primavera de 1987 ” (2004, p. 24).

Trabalhar com a materialidade dos suportes implica conceder importância aos objetos e pensá-los enquanto parte de uma rede, que engloba todos os atores responsáveis por uma ação. $\mathrm{Na}$ perspectiva hermenêutica, essa concessão não seria possível, uma vez que é o homem o senhor de todos os objetos e quem lhes atribui 
sentido. Assim, por exemplo, o ato de apreciar uma imagem no Instagram implica uma conjunção entre fotógrafo, fotografado, câmera (celular ou tablet), filtros utilizados, ambiente de captura da imagem (ao ar livre, em casa, em uma festa, em um estádio etc.), espectador, suporte de visualização, formando uma verdadeira rede sociotécnica, nos termos latourianos ${ }^{4}$. Esse desvio no foco de análise para fatores externos ao produto comunicacional é um ponto que deve ser enfatizado. Pensar o jornal, a fotografia, a TV, a internet náo somente pelos seus conteúdos, mas, sim, em sua materialidade e nos efeitos que essa experiência de recepção diferenciada causa no público. Reiteramos que ainda que próximas e em diálogo, a teoria das materialidades não deve ser confundida com a teoria ator-rede de Bruno Latour.

\section{Breve estado da arte dos estudos sobre esporte/futebol e a con- tribuição de Gumbrecht para o campo}

Inicialmente, na década de 1970, durante o regime militar no Brasil, o futebol era trabalhado por poucos autores das Ciências Sociais no país e sempre com um viés apocalíptico. Era uma situação de descaso mesclado com críticas - uma consequência direta da influência marxista no período, sintetizada pela frase: "o futebol é o ópio do povo". Podemos citar o livro Futebol: ideologia do poder de Roberto Ramos como exemplar do cunho marxista predominante. Ramos (1984) trabalha o futebol enquanto aparelho ideológico do estado, apropriando-se do conceito original de Althusser. Posição mais branda, mas igualmente crítica, tem José Carlos Rodrigues. Em seu artigo "O rei e o rito" (1982), o antropólogo brasileiro adota uma perspectiva crítica em relação à construção da figura mítica de Pelé, que, segundo ele, esconde uma tentativa de imposição de uma "reverência a uma imagem politicamente forjada da sociedade” (1982, p. 18). O objetivo central de Rodrigues é interpretar a festa de despedida de Pelé como um rito.

Ainda que o vissem como "perverso", esses autores apocalípticos do futebol defendiam mais estudos sobre o tema, como Joel Rufino dos Santos, no artigo "Na CBD até o papagaio bate continência" (1978). A evocação desse descaso ao futebol como objeto de análise sociológica era lugar-comum no início de toda obra que trabalhasse com o tema.

O primeiro trabalho a romper com essa lógica apocalíptica foi Universo do Futebol: esporte e sociedade brasileira (1982), organizado pelo antropólogo Roberto DaMatta. Sua importância não se esgota no ineditismo do livro, mas no que ele representou para todo um campo de estudos ainda recente. O nome de DaMatta, já reconhecido nacionalmente, agregou prestígio e relevância aos estudos sobre esporte. Além disso, ele trouxe uma nova perspectiva teórica, que lidava com o esporte enquanto "drama da vida social", e não mais como mero instrumento político a serviço das elites políticas e da classe dominante. $\mathrm{O}$ futebol, para o antropólogo brasileiro, era visto como um instrumento válido para se entender a sociedade brasileira (um meio para se atingir dado fim).

Antes dessa obra emblemática de DaMatta, Muniz Sodré, no último capítulo de O Monopólio da Fala (1977), apesar de seu tom marcadamente pessimista, já apresentava sinais de um olhar mais benevolente em relação ao esporte, como no excerto: "a torcida (...) faz parte necessária do show” (SODRÉ, 
1977, p. 141). Helal salienta que "o texto de Sodré [...] talvez tenha sido a primeira análise acadêmica sobre futebol inserida mais clara e assumidamente dentro da área da "Teoria da Comunicação”" (2011, p. 17).

O debate entre Soares, Helal e Gordon, reunido no livro $A$ invenção do país do futebol (2001), foi peremptório para dotar de maior seriedade e apuro científico às investigaçóes sociais em torno do futebol. O primeiro criticava a postura de alguns intelectuais e jornalistas que utilizavam o livro O Negro no Futebol Brasileiro (1947) como fonte histórica única e inquestionável para seus escritos. Enquanto os outros dois defendiam uma relativizaçáo dessa perspectiva: não citar de forma acrítica, mas continuar utilizando a obra de Mário Filho com ressalvas, contextualização do período em que o livro foi escrito e maior apuro teórico.

Um ponto recorrente dos estudos está no diálogo entre futebol e identidade nacional. Inúmeros artigos e livros em Ciências Sociais foram produzidos sobre o tema Inicialmente, destacava-se a importância daquele esporte para a construção de um ethos nacional, enquanto atualmente estaríamos vivenciando uma diminuição nessa associação. A fonte básica para essas análises era o discurso midiático, principalmente através dos jornais impressos, em época de Copa do Mundo.

Assim, vemos como o futebol segue uma trajetória que vai do ocaso até o destaque como temática válida dentro das Ciências Sociais, passando de ópio do povo à drama social e, finalmente, um meio para entender a cultura e a sociedade. Todas as perspectivas e abordagens, por mais diversas e contraditórias, tiveram sua importância para o desenvolvimento do campo. É válido destacar que, em 2010 e 2011, diversas revistas na área de Comunicação dedicaram dossiês à temática de esporte, como, por exemplo, a Organicom (USP), a Logos (Uerj) e a Comunicação, Mídia e Consumo (ESPM). Além disso, o Intercom 2012 também deu destaque às pesquisas sobre esporte, adotando como tema geral "Esportes na Idade Mídia: Diversão, Informação, Educação".

De modo geral, as obras utilizadas como referência pelos autores brasileiros nessa breve história dos estudos acadêmicos sobre Esporte focam-se no paradigma hermenêutico e em uma cultura de sentido. Para explicitar esse pouco uso de autores da materialidade e o predomínio da hermenêutica, efetuamos uma análise das bibliografias utilizadas em todos os artigos apresentados no GP Comunicação e Esporte (dentro do DT 6 - Interfaces Comunicacionais) do Intercom Nacional 2011, realizado no Recife. No total, foram coletados 24 artigos, que juntos somaram 346 entradas bibliográficas. Desse total, apenas um fazia menção à obra de um autor das materialidades - Gumbrecht -, a saber: "O espetáculo do futebol" de Marcio Telles e Fabrício Silveira. Se considerarmos McLuhan como um autor antecipador de alguns pressupostos da teoria das materialidades, teríamos mais um artigo: "A internet como meio de protesto" de Andréia Gorito. Por outro lado, os autores da sociologia clássica são mais lembrados, por exemplo: Hobsbawm tem suas obras citadas em quatro ocasióes; Pierre Bourdieu, em três; Stuart Hall, em duas; Guy Debord, em quatro. 
Nesse momento, faz-se necessário expormos rapidamente qual seria a contribuição da obra de Gumbrecht aos estudos sobre esporte. Antes, porém, falaremos rapidamente quem é esse teórico alemão.

\section{Quem é Gumbrecht?}

A Discípulo de Hans Robert Jauss, na Universidade de Bochum, Gumbrecht fez parte da segunda geração da Escola de Constança, que defendia uma estética da recepção ${ }^{5}$ como teoria e método literários. Desde 1989, professor de literatura comparada da Universidade de Stanford nos EUA, ele conta com uma formação acadêmica globalizada, tendo estudado em Paris, Munique, Salamanca, Constança, além de periodicamente, desde a década de 1970, vir ao Brasil ministrar cursos e palestras ${ }^{6}$. Com 26 anos, já havia obtido a certificação acadêmica alemã (Habilitationsschrift) que lhe permitia orientar doutores - válido enfatizar o quão difícil é obtê-la; Walter Benjamin, por exemplo, não a conseguiu (ROCHA, 1998, p. 7). Seus interesses são tão plurais quanto sua formação, passando dos esportes à política, tendo como suporte teórico tanto a filosofia quanto a história e a literatura. Seus trabalhos convergem "em torno da rubrica das 'materialidades da comunicação"” (SILVEIRA, 2010, p. 184). Sua busca é por uma maior igualdade, de atenção e de quantidade de trabalhos, entre os paradigmas hermenêuticos (ou clássico) e não-hermenêuticos. Em uma linha evolutiva dos estudos de mídia, podemos dizer que Gumbrecht resgata o ideário mcluhaniano, que aproxima os meios de comunicação da experiência sensível.

Ainfluência da teoria das materialidades perpassa todos os textos de Gumbrecht utilizados como base para o presente artigo. Ele reitera, sempre que possível, que "[...] é um equívoco crer que as humanidades e as artes devam lidar exclusivamente com fenômenos constituídos de significação e não com fenômenos baseados na substância” (2011a, p. 3). Destaca também a importância do fascínio exercido pelo esporte sobre as pessoas para a continuidade e o sucesso do mesmo. Sem essa vontade e prazer dos torcedores em estarem presentes nos eventos esportivos, esses, com certeza, não ocupariam o lugar de destaque que hoje possuem em nossa sociedade. Não podemos esquecer de mencionar o caráter crítico relacionado ao esporte que permeia alguns trechos de sua obra, afastando-se do tom almejado por sua história descritiva?

Ressaltamos ainda a visão diferenciada do esporte efetuada por Gumbrecht, através das noçóes de materialidade e presença, buscando nele um signo para experiências estéticas, e não apenas um meio para a produção de sentidos. Daí, a ênfase na observação dos corpos e de sua perfeição atlética, que nos proporcionariam prazeres efêmeros, inexplicáveis hermeneuticamente e extra-cotidianos. A dimensão da presença se concretizaria na assistência ao vivo de um espetáculo esportivo, dotado de beleza artística singular, distinta de outras esferas da arte e da cultura. Pensar o esporte, pelo viés da teoria das materialidades, implica considerar as condiçôes sócio-históricas e materiais da recepção (no estádio, em casa, no bar, pela $\mathrm{TV}$, pelo rádio), e a produção de presença que lhe é inerente.

Destacamos, porém, que Gumbrecht não exclui essa dimensão interpretativa. Ele apenas postula que algumas experiências prescindem dessa interpretação - assim, seriam mais sensação do que sentido. No caso do esporte, ele tende a crer que 
dimensão de presença seria maior que a de significado. Mas ele não opta pelo caminho mais fácil teoricamente de substituir, de modo excludente, uma pela outra. Antes, tenta conciliar as duas perspectivas, destacando mais, é claro, aquela que diz respeito a seu corpus teórico de referência - a presença. Ressaltamos também que Gumbrecht sempre procura relativizar suas afirmaçóes, evitando cair em determinismos, justamente um dos fatores que critica na hermenêutica. Ele não afirma que as Ciências Sociais devam lidar somente com objetos que sejam essencialmente permeados de presença. Pelo contrário, ao longo de todo o livro Produção de Presença (2010), ele afirma que alguns objetos e culturas parecem ser mais propícios a uma análise pelo viés da presença, enquanto outros, realmente, devem ser lidos pela hermenêutica.

As imagens do esporte também produzem presença, como ficará melhor demonstrado nos tópicos seguintes.

\section{Produzindo presença no Instagram}

O Instagram ${ }^{8}$ é uma ferramenta gratuita de compartilhamento de imagens para celulares e tablets com sistema operacional iOS (gadgets da Apple) e Android?. Por meio dessa aplicação é possível adicionar filtros às fotos tiradas, que remetem à estética da fotografia analógica (cores esmaecidas ou que remetem ao processo cruzado de revelaçãoo ${ }^{10}$ são alguns deles). $\mathrm{O}$ formato quadrado (proporção 3:2) das fotos produzidas também é característico das antigas câmeras instantâneas Polaroid (é interessante observar que o ícone do aplicativo é uma dessas máquinas fotográficas em miniatura, uma referência explícita a elas por parte dos desenvolvedores).

Lançado em 2010, o Instagram tinha uso limitado aos celulares iPhone. Pouco tempo depois de ser comprado pelo Facebook - em abril de 2012, em uma transação histórica na Internet, no valor de 1 bilhão de dólares - foi liberado para usuários do sistema Android ${ }^{11}$, tornando-se mais popular. Hoje há mais de 50 milhôes de usuários ao redor do mundo.

Além da questão estética das fotos, o aplicativo é também uma rede social, sendo possível comentar e "curtir" as fotos - embora também possua integração com Facebook, Twitter, Foursquare e Flickr, permitindo a divulgação das imagens também em redes exteriores a ele. $\mathrm{O}$ texto divulgado por seus criadores no site oficial atribui à ferramenta uma característica de comunhão por meio de imagens: "estamos construindo o Instagram para que você possa experimentar momentos da vida de seus amigos através de suas imagens. Imaginamos um mundo mais conectado através de fotos" ${ }^{\prime 2}$. Também há um sistema de tagging, semelhante ao do Twitter, através do qual é possível buscar fotos que foram marcadas por determinadas hashtags (como a \#finallibertadores, que analisamos nesse trabalho).

Nesse artigo relacionamos o Instagram à perspectiva gumbrechtiana, considerando o aplicativo como um "produtor de presença”: "[...] é verdade que alguns 'efeitos especiais' produzidos hoje pelas tecnologias de comunicação mais avançadas podem revelar-se úteis no re-despertar do desejo de presença" (GUMBRECHT, 2010, p. 15). A “intensidade da concentração" (GUMBRECHT, 2007, p. 45) no esporte poderia ser registrada por uma foto, que congelaria esse momento único de êxtase, sem, contudo, ser capaz de voltar a reproduzi-lo em toda sua intensidade. A materialidade da 
experiência se faz aqui presente. A presença produzida pela assistência do espetáculo esportivo ao vivo é, para Gumbrecht, especial e incomparável. Ao transpormos para outro suporte, como a TV, o papel, o celular ou o tablet, ela transmitiria uma experiência distinta daquela originalmente vivida pelos presentes no estádio.

\section{A narrativa da final da Libertadores 2012 por torcedores no Instagram}

\section{Notas sobre a pesquisa}

Nesta etapa do trabalho, propomos uma metodologia para análise das imagens do Instagram sobre um assunto específico. Aqui, dada a temática do artigo, abordamos a final da Taça Libertadores da América de 2012, disputada entre Corinthians e Boca Juniors. Para tal, selecionamos quatro tags: \#finallibertadores (75 fotos), \#finallibertadores2012 (3 fotos), \#corinthiansxboca ${ }^{13}$ (82 fotos) e \#corinthiansxbocajrs ${ }^{14}$ (8 fotos). No total, até o dia 28/07/2012, as quatro tags totalizavam 168 fotos $^{15}$. Inicialmente, atuando como um filtro preliminar para a análise principal, efetuamos uma análise de conteúdo, estabelecendo categorias para as imagens. Essa tipologia será peremptória para a descrição subsequente, partindo do princípio que as imagens são capazes de nos contar uma história - no caso, o relato da final do torneio.

Digno de menção é a busca por visibilidade utilizando hashtags que estão em voga, a fim de divulgar sua imagem entre outras mais vistas da rede, assim como já ocorre no Twitter. Nesses casos, fica evidente a ordenação das tags priorizando outras que não aquelas referentes ao jogo em si. Por exemplo, estava em nosso corpo de análise a foto de quatro amigos em roupas triviais, sem nenhuma referência clubística. As tags utilizadas para marcar a foto foram ordenadas da seguinte forma: \#amigos, \#irmãos, \#companheiros, \#prasempre, \#finallibertadores, \#prime. Isso revela, de certa forma, o desejo de promover a amizade do quarteto por meio de um evento em destaque na rede mais do que demonstrar amor e apoio ao clube.

Percebemos, de forma marcante, como as fotos do Instagram capturam sentimentos comuns à assistência ao vivo do futebol e são eles que utilizamos para descrever o que foi o jogo. $\mathrm{Na}$ narrativa dos jornais, o Corinthians empatou o primeiro jogo da final $(1 \mathrm{x} 0)$ e ganhou o segundo jogo por 2x0, conquistando sua primeira Taça Libertadores. Na narrativa imagética, os protagonistas são os torcedores que experienciaram a vitória com um misto de sensaçóes e sentimentos.

\section{Estabelecendo categorias}

Nessa análise de conteúdo, elaboramos quatro categorias, que nos permitem ter uma visão panorâmica do universo de imagens trabalhada. Importante destacar que aqui se evidencia o caráter mais estético do Instagram, isto é, a multiplicidade de formas de imagem possíveis de ser encontradas e os diversos filtros, enquadramentos e formas presentes. Sendo assim, propomos a seguinte 
tipologia: 1) torcida (fotos da torcida no estádio ou de pessoas em ambientes públicos, como bares, ou em seus lares com vestimentas alusivas aos clubes finalistas ou a rivais); 2) exibicionismo (fotos de si, sem ou com ínfima referência ao clube); 3) hibridismo (fotos tiradas da tela da TV, do computador ou celular); 4) avulsas (escudos de clube, memes, pôsteres, provocaçôes) ${ }^{16}$.

Dito isso, expomos abaixo os resultados obtidos e um quadro com exemplos emblemáticos das quatro categorias
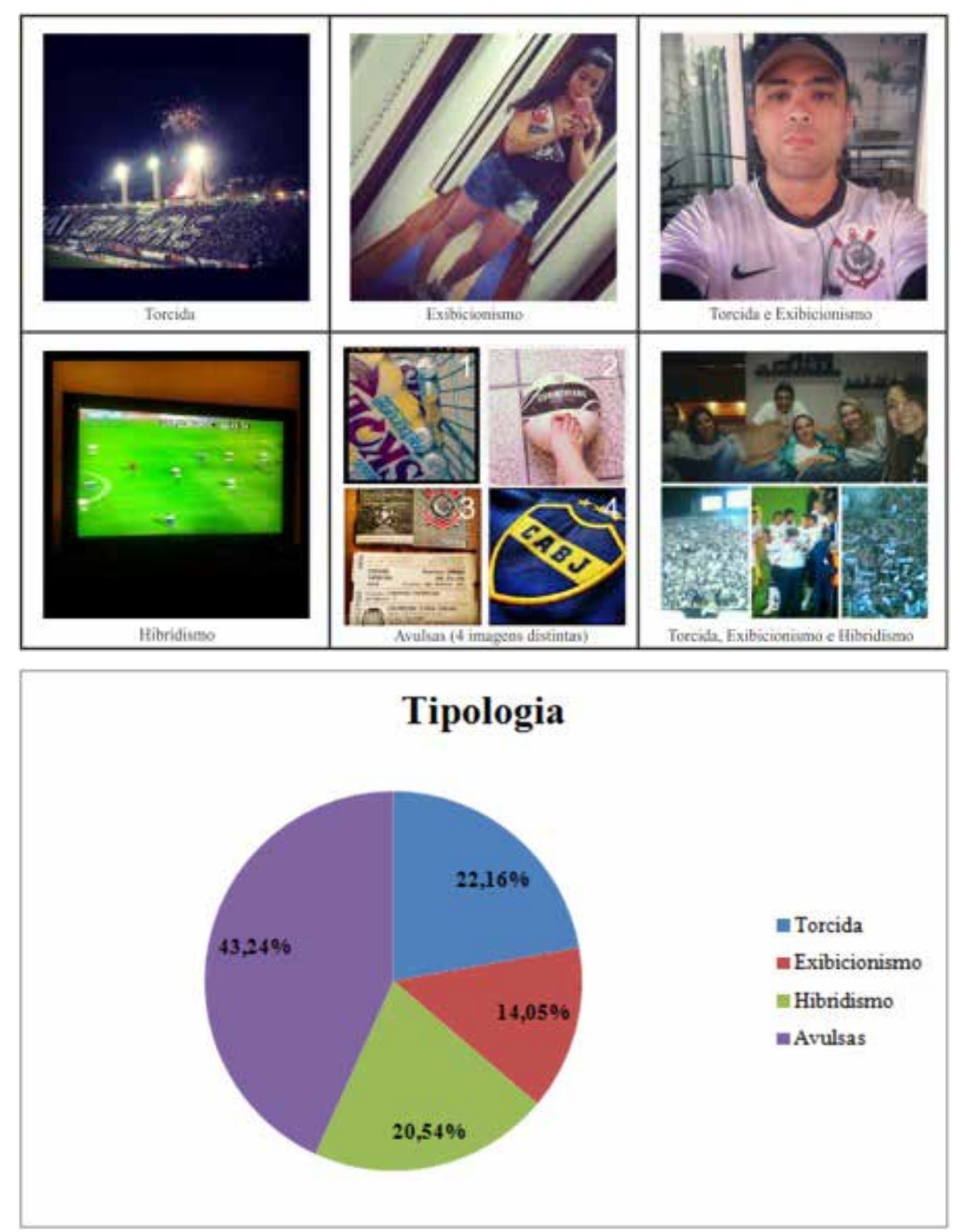

\section{O jogo pelas imagens dos torcedores}

Feita a breve distinção tipológica acima, utilizaremos agora o potencial do Instagram enquanto suporte de memória. Acreditamos ser possível recontar um episódio a partir das imagens que foram produzidas sobre ele e "subidas" ao aplicativo. Gumbrecht, em seu livro Elogio da Beleza Atlética (2007), critica a falta de obras sobre história do esporte que enfocassem a "presença" nesses espetáculos: "A maioria dos livros e ensaios sobre a história do esporte está cheia de relatos biográficos ou dados cronológicos, mas raramente oferece materiais ou até sugestóes para nossa imaginação visual" (2007, p. 69). Desse questionamento, nós propusemos outro: por que não 
pensar um acontecimento histórico do futebol sob a perspectiva de imagens e dos sentimentos ali expostos? E, indo além, uma história produzida pelos torcedores, o polo receptor do espetáculo esportivo, já que são eles que "alimentam" o Instagram com imagens. Contemplamos assim a dimensão do esporte assistido, e não apenas do esporte praticado (cf. Gastaldo 2004, 2006 apud TELLES; SILVEIRA, 2011, p. 8).

As categorias expostas anteriormente nos ajudaram a entender quais momentos e propósitos são mais prezados pelos torcedores. A partir delas, traçamos uma linha não sequencial dos sentimentos presentes nessas imagens. Longe de ser fruto de uma interpretação profunda das fotos, esses sentimentos estão na dimensão da presença. São expressóes que saltam aos nossos olhos assim que nos atemos à imagem no visor de nosso smartphone ou tablet. Buscamos aqui produzir presença através das imagens (materialidade imagética) e propiciar um reviver da partida.

Vamos à narrativa:

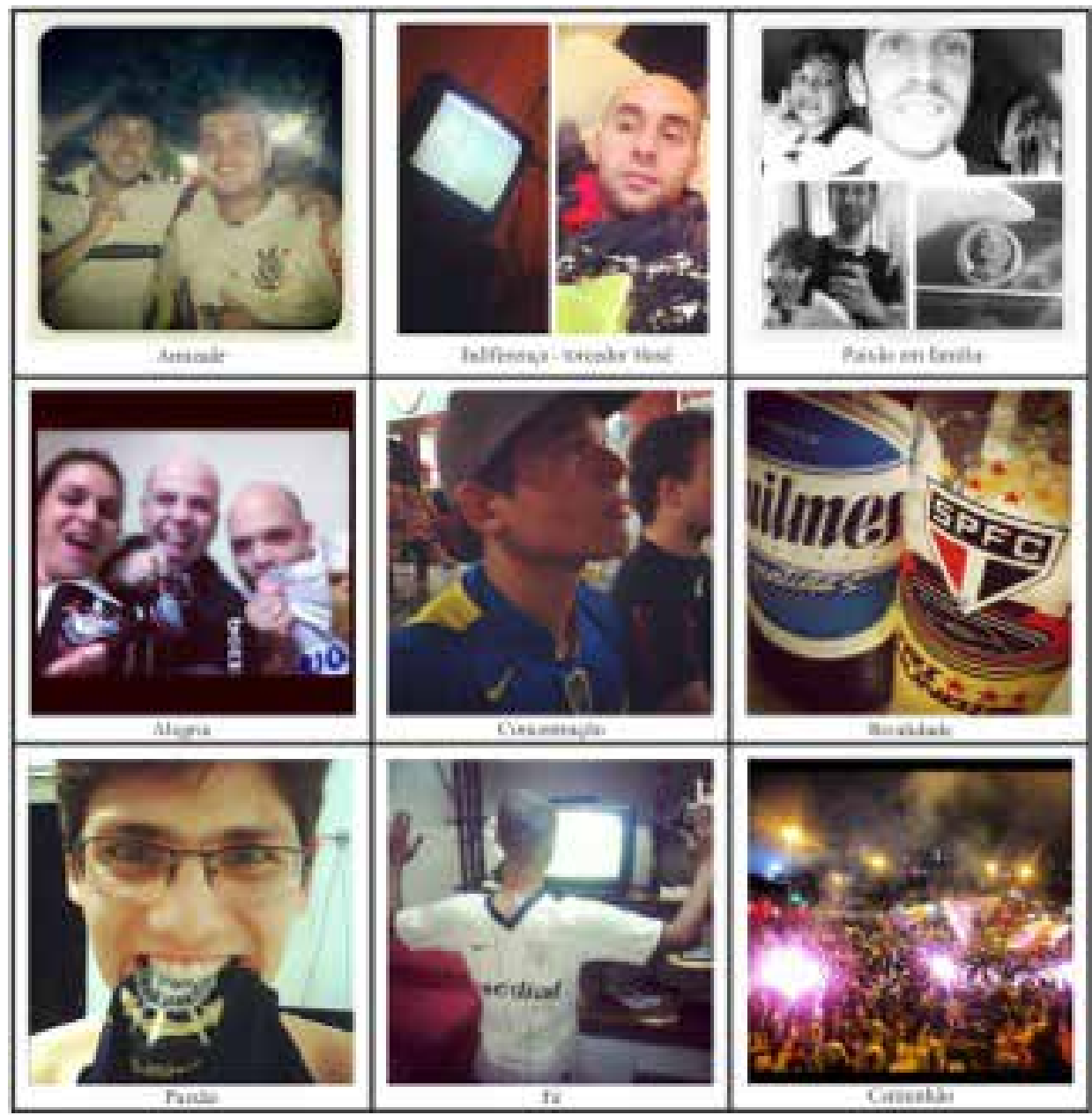

\section{Considerações finais}

Neste artigo, conseguimos entrar em contato com um corpo teórico relativamente novo e pouco utilizado nos trabalhos em Comunicação que enfocam o esporte como tema. Utilizar o Instagram como objeto e fonte de 
dados foi outra, "digamos", novidade, tanto para nós quanto para o campo da Comunicação e Esporte. A teoria das materialidades e o objeto pesquisado (tags de um evento esportivo no Instagram) mostraram-se profícuos para outras futuras incursóes.

Após a realização da pesquisa empírica algumas observações sobre as formas de apropriação do aplicativo de imagens pelos torcedores vieram à tona: 1) os usuários postam mais fotos da tela da TV do que do campo de jogo, o que nos permite afirmar que assistem ao jogo principalmente de casa e que não se preocupam muito com uma pretensa beleza artística das imagens capturadas; 2) há um alto grau de exibicionismo entre os usuários, que optam por tirar fotos que enfatizam mais seus corpos e rostos do que o emblema e as cores do seu time do coração; 3) são retratadas múltiplas formas de torcer que reproduzem em imagens estáticas os sentimentos envolvidos na experiência estética "real" (no estádio) e ao vivo (mediada pelo suporte televisivo em lares ou espaços públicos); 4) a partir do Instagram é possível reviver, por meio das emoçóes presentes nas fotos dos usuários, o que foi o evento esportivo; 5) há um número considerável de memes, pôsteres e imagens não produzidas pelos próprios usuários do aplicativo, mas apenas compartilhadas por eles, o que desvirtua, de certo modo, o objetivo inicial do Instagram.

Poderíamos continuar indefinidamente traçando conjecturas sobre a apropriação do Instagram pelos torcedores, mas cremos que aquelas aqui avultadas já nos permitem perceber como a interface Instagram e Esporte pode ser afetada positivamente pela teoria das materialidades da comunicaçáo e, a partir de suas proposiçóes, construir novos corpus de pesquisa, enfoques temáticos e investigaçôes epistemológicas. Terminamos por concluir que o esporte, sendo fundado no corpo, e o Instagram, pela materialidade dos suportes e das imagens, são exemplares de uma cultura de presença na contemporaneidade. Mesmo sem nos preocuparmos tanto com as motivaçôes "profundas" dos usuários, o que seria hermenêutico demais, foi possível extrair uma instigante análise das imagens a partir dos sentimentos "presentes" em sua camada mais superficial, acessível a um olhar interessado não em sentidos, mas, sim, em presença.

\section{Referências Bibliográficas}

DANTONIOLLI, Juliano; BATALHONE, Vitor. Entrevista com Hans Ulrich Gumbrecht. Aedos, v. 2, n. 5, Julho-Dezembro 2009.

ARAUJO, Valdei Lopes de. Para além da auto-consciência moderna: a historiografia de Hans Ulrich Gumbrecht. Varia Historia, Belo Horizonte, v. 22, n. 36, p.314-328, Jul./Dez. 2006.

BENJAMIN, Walter. A obra de arte na era de sua reprodutibilidade técnica. In: ADORNO et al. Teoria da Cultura de massa. Trad. de Carlos Nelson Coutinho. Sáo Paulo: Paz e Terra, 2000. p. 221-254.

CALLON, Michel; Law, John. After the individual in society: lessons on collectivity from science,technology and society. In: Canadian Journal of Sociology, Spring, v. 22, n.2, p. 165-82, 1997. 
DAHER, Andrea. Panfleto contra 'tédio' da teoria. Caderno Prosa e Verso, O Globo, 19 fev. 2011a, p. 3.

Equívoco da equivalência. Caderno Prosa e Verso, O Globo, 05 mar. 2011b, p. 5.

DAMATTA, Roberto (org.). Universo do futebol: esporte e sociedade brasileira. Rio de Janeiro: Pinakotheke, 1982.

GUMBRECHT, Hans Ulrich. Produção de presença. Contraponto/ PUC-Rio, 2010, Rio de Janeiro.

. Corpo e Forma. Ensaios para uma crítica não-hermenêutica. Org: João Cesar de Castro Rocha. Rio de Janeiro, EDUERJ, 1998.

. Elogio da Beleza Atlética. São Paulo: Cia. das Letras, 2007.

Uma questáo de sentido. Caderno Prosa e Verso, O Globo, 26 fev. 2011a, p. 3.

. Uma segunda resposta 'cordial'. Caderno Prosa e Verso, O Globo, 12 mar. 2011b, p. 5.

HANKE, Michael. A Materialidade da Comunicação: um conceito para a ciência da comunicação?. Interin (Curitiba), v. 1, p. 1-8, 2006.

HELAL, RONALDO. Futebol e Comunicação: a consolidação do campo acadêmico no Brasil. Comunicação, Mídia e Consumo. São Paulo, v. 8, p. 11-37, 2011.

LATOUR, Bruno. Jamais Fomos Modernos. Rio de Janeiro: 34 letras, 1994.

Reassembling the social. An Introduction to Action-NetworkTheory. Nova Iorque: Oxford University Press, 2005.

RAMOS, Roberto. Futebol: Ideologia do poder. Petrópolis: Vozes, 1984.

ROCHA, Joáo Cezar de Castro. A materialidade da teoria. In: GUMBRECHT, Hans Ulrich. Corpo e Forma. Ensaios para uma crítica não-hermenêutica. Org: João Cesar de Castro Rocha. Rio de Janeiro: EDUERJ, 1998.

RODRIGUES, José Carlos. O Rei e o Rito. Revista Comum, n. 1, jan./ mar. 1982, p.16-29.

SÁ, Simone. Exploraçôes em torno da noção de materialidade da comunicação. In: XXVII Congreso Brasileiro de Ciências da Comunicação, 2004, Porto Alegre. Anais da XXVII Intercom: Comunicaçáo, Acontecimento e Memória. Porto Alegre : Intercom, 2004.

SANTOS, Joel Rufino. "Na CBD até o papagaio bate continência". In: Encontros com a Civilização Brasileira, número 5, Rio de Janeiro, Civilização Brasileira, 1978,

SILVEIRA, Fabrício. Além da atribuição de sentido. Verso e Reverso, v. 24, n. 57, p. 183-186, setembro-dezembro 2010.

SHAVIRO, Steven. The Universe of Things. Disponível em: <http:// 
www.shaviro.com/ Othertexts/Things.pdf>. Acesso em: 10 jul. 2012.

SODRÉ, Muniz. "Futebol, Teatro ou Televisão". In: SODRÉ, Muniz. O monopólio da fala. Petrópolis: Vozes, 1977.

TELLES, Márcio; SILVEIRA, Fabrício. O espetáculo do futebol: experiência estética e experiência midiática. In: XXXIV Congresso Brasileiro de Ciências da Comunicação, 2011, Recife. Anais da XXXIV Intercom. Quem tem medo de pesquisa empírica?. Recife: Intercom, 2011.

\section{Notas}

1. Para uma discussão sobre conceito de Moderno ao longo da História, baseada na reflexão de Gumbrecht, ver o artigo de Araújo (2006).

2. Esclarecemos o sentido em que utilizamos essa palavra ao longo do texto: "Interpretar o mundo quer dizer ir além da superfície material ou penetrar nessa superfície para identificar um sentido (isto é, algo espiritual) que deve estar atrás ou por baixo dela" (GUMBRECHT, 2010, p. 48).

3. Para uma crítica dessa obra, sugerimos a leitura da resenha de Daher e de sua tréplica (2011a, 2011b), bem como da resposta de Gumbrecht à resenha e à tréplica (2011a, 2011b). Nesse debate, de argumentos apaixonados de ambos os lados, destacamos a diferenciação que Daher (2011b) expõe entre sentido e significado e a explicação de Gumbrecht para como essa dicotomia epistemológica aparece em sua obra. Disponível em: <http://observatoriodacritica.com.br/polemicas/polemica-entreandrea-daher-e-hans-ulrich-gumbrecht/>. Acesso em: 09 jul. 2012.

4. Exemplificando essas redes sociotécnicas ou coletivos híbridos, Bruno Latour cita a "rede Pasteur". "O argumento [de Latour] é que Pasteur não era uma única entidade, não somente um corpo e uma alma [...] Ele, ao invés disso, era a combinação de um grande número de diferentes elementos que produziram o grande-pesquisadorPasteur" (CALLON; LAW, 1997, p. 3, tradução nossa). Esses dois autores, Callon e Law, são contundentes ao afirmar que "Pessoas são redes. Dispositivos são redes." (1997, p. 3, tradução nossa). Nesse exemplo, vemos os objetos dotados de agência e em constantes associaçóes com os entes humanos.

5. Em poucas palavras, essa corrente acadêmica, inaugurada por Jauss em oposição ao estruturalismo então em voga, foca no leitor e nas condiçóes sociohistóricas em que sua leitura se processa.

6. Para entender um pouco da influência brasileira em Gumbrecht e de seu afeto pelo nosso país, ver Antoniolli e Batalhone (2009).

7. Sobre isso, é interessante notar que o próprio Gumbrecht é reticente quanto às suas reais condiçôes de fazê-lo, vejamos: "No que segue, eu gostaria de me abster de julgamentos de valor. No entanto, como minha 'socializaçáo intelectual' teve lugar na tradição alemã, sou levado a considerar qualquer esperança de realizar este desejo como ingênuo" (1998, p. 118). No livro Em 1926: vivendo no limite do tempo, logo nas primeiras linhas, ele esclarece seu modus operandi, que se assemelha muito à sua proposta de história descritiva e a uma ética não-hermenêutica: "Cada verbete abstém-se tanto quanto possível de 'expressar' a voz individual do autor, de interpretaçóes profundas e de contextualizaçôes” (GUMBRECHT, 1999, p. 9). 
8. O nome é uma junção dos termos da língua inglesa "instant" e "telegram", referência às imagens como forma de enviar mensagens a outras pessoas. Endereço oficial disponível em: <http://www.instagram.com>.

9. Apesar de ter sido desenvolvido originalmente para uso exclusivo em dispositivos móveis, o aplicativo foi apropriado não oficialmente por alguns sites para utilização em desktopse notebooks, como é o caso do Webstagram e também do plugin Instagram for Chrome, que permite a visualização da timeline no próprio navegador.

10. Essa prática consiste na revelação de um filme cromo utilizando a química própria para filmes negativos (C-41). Esse "erro proposital" torna as cores das fotos mais vivas, com fortes tons amarelados e esverdeados.

11. Inicialmente, usuários da versão para iPhone não gostaram da notícia, pois não queriam a popularização do aplicativo (já que gostavam de ter exclusividade), o que gerou uma rixa com os novos usuários.

12. Tradução nossa. Texto original disponível em: <http://instagram.com/about/faq/> Acesso: 25 Jul. 2012.

13. Não analisamos uma foto, postada pela usuária shirleyfarias, por estar presente também na tag \#finallibertadores.

14. Não analisamos uma foto, postada pelo usuário felipehenrique, por estar presente também na tag \#finallibertadores.

15. Esse número refere-se às fotos abertas ao público, já que há perfis privados que só podem ser visualizados por usuários autorizados. Assim, o número do de fotos informadas pelo Instagram em uma tag nem sempre é o número real, ou seja, o número de fotos abertas a visualização de todos.

16. 16 Algumas fotos podem pertencer a mais de uma das categorias definidas neste trabalho. Por exemplo, algumas fotos de "torcida" apresentavam também traços característicos de "exibicionismo". 